Linköping Studies in Science and Technology

Thesis No. 1784

\title{
Modelling Weather Dynamics for Weather Derivatives Pricing
}

\author{
Emanuel Evarest Sinkwembe
}

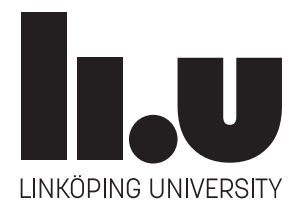

Mathematical Statistics

Department of Mathematics

Linköping University, SE-581 83 Linköping, Sweden

Linköping 2017 
Linköping Studies in Science and Technology. Thesis No. 1784 Licentiate Thesis

(C) 2017 Emanuel Evarest Sinkwembe

Division of Mathematical Statistics

Department of Mathematics

Linköping University

SE-581 83, Linköping, Sweden

emanuel.evarest@liu.se

www.mai.liu.se

Typeset by the author in $\mathrm{H}_{\mathrm{E}} \mathrm{X} 2 \mathrm{e}$ documentation system.

ISSN 0280-7971

ISBN 978-91-7685-473-0

Printed by LiU-Tryck, Linköping, Sweden 2017 


\section{Abstract}

This thesis focuses on developing an appropriate stochastic model for temperature dynamics as a means of pricing weather derivative contracts based on temperature. There are various methods for pricing weather derivatives ranging from simple one like historical burn analysis, which does not involve modeling the underlying weather variable to complex ones that require Monte Carlo simulations to achieve explicit weather derivatives contract prices, particularly the daily average temperature (DAT) dynamics models. Among various DAT models, appropriate regime switching models are considered relative better than single regime models due to its ability to capture most of the temperature dynamics features caused by urbanization, deforestation, clear skies and changes of measurement station. A new proposed model for DAT dynamics, is a two regime switching models with heteroskedastic mean-reverting process in the base regime and Brownian motion with nonzero drift in the shifted regime. Before using the model for pricing temperature derivative contracts, we compare the performance of the model with a benchmark model proposed by Elias et al. (2014), interms of the HDDs, CDDs and CAT indices. Using five data sets from different measurement locations in Sweden, the results shows that, a two regime switching models with heteroskedastic mean-reverting process gives relatively better results than the model given by Elias et al. We develop mathematical expressions for pricing futures and option contracts on HDDs, CDDs and CAT indices. The local volatility nature of the model in the base regime captures very well the dynamics of the underlying process, thus leading to a better pricing processes for temperature derivatives contracts written on various index variables. We use the Monte Carlo simulation method for pricing weather derivatives call option contracts. 



\section{Sammanfattning}

Denna avhandling fokuserar på att utveckla en lämplig stokastisk modell för temperaturdynamik som ett sätt att prissätta väderderivatkontrakt baserat på temperatur. Det finns olika metoder för att prissätta väderderivat som sträcker sig från enkla som historisk brännaanalys, vilket inte innebär att man modellerar det underliggande Vädervariabel till komplexa som kräver Monte Carlo-simuleringar för att uppnå tydliga väderderivatkontraktspriser, särskilt det dagliga genomsnittet Temperatur (DAT) dynamik modeller. Bland olika DAT-modeller betraktas lämpliga regimekopplingsmodeller relativt bättre än enkla regimodeller på grund av dess förmåga att fånga in de flesta av de Temperaturdynamiska egenskaper som orsakas av urbanisering, avskogning, klar himmel och förändringar av mätstationen. En ny föreslagen modell för DAT-dynamik är en två Regimbytesmodeller med heteroskedastisk medelåterställningsprocess i basregimen och brunisk rörelse med ojämn drift i den förskjutna regimen. Innan du använder Modellen för prissättning av temperaturderivatkontrakt, jämför vi modellens prestanda med en referensmodell som föreslagits av Elias it et al. (2014), interms Av hårddisken, CDD och CAT-index. Genom att använda fem dataset från olika mätställen i Sverige visar resultaten att en tvåreglermodell med Heteroskedastisk medelåterställningsprocess ger relativt bättre resultat än modellen som ges av Elias it et al. Vi utvecklar matematiska uttryck för prissättning av futures och optionsavtal på hårddiskar, CDD och CAT-index. Den lokala volatilitetsegenskapen för modellen i Basregimen tar väldigt bra dynamiken i den underliggande processen, vilket leder till bättre prissättningsprocesser för temperaturderivatkontrakt skrivna på Olika indexvariabler. Vi använder Monte Carlo-simuleringsmetoden för prissättning av väderderivat köpoptionsavtal. 



\section{Acknowledgments}

I would like to thank my supervisors Martin Singull, Fredrik Berntsson and Xiangfeng Yang for their guidance, support, remarks and constructive comments throughout the writing of this thesis. They have been always available whenever I needed their advice and support.

Also, I would like to thank Bengt Ove Turesson, Björn Textorius, Theresa Lagali, Meaza Abebe and all other members of the Department of Mathematics for their help in different matters.

I would like to thank International Science Programme (ISP) for financial support through Eastern Africa Universities mathematics Programme (EAUMP). Particularly, I am very thankful to Leif Abrahamsson, Pravina Gajjar, Eunice Mureithi and Sylvester Rugeihyamu for their facilitation.

I am very thankful to my wife and our children for their moral and emotional support as well as encouragement during the whole period of working on this thesis.

I also thank my fellow $\mathrm{PhD}$ students whom we shared different good moments together. 



\section{Contents}

1 Introduction 1

1.1 General Introduction . . . . . . . . . . . . . . . . . . . . . . . . . 1

1.2 Statement of the Problem . . . . . . . . . . . . . . . . 2

1.3 Thesis Structure . . . . . . . . . . . . . . . . . . . . 3

1.3.1 Summary of Papers . . . . . . . . . . . . . . . 3

2 Theoretical Background 5

2.1 Weather Derivatives and Weather Indices . . . . . . . . . . . . . . 5

2.1.1 Weather Derivatives Contracts . . . . . . . . . . . . . . 7

2.2 Stochastic Calculus . . . . . . . . . . . . . . . . . . . . 8

2.2.1 Itô Processes and its Applications . . . . . . . . . . . . . . . . . . 11

2.2.2 Change of Measure and Girsanov's Theorem . . . . . . . . . . . . . . 13

2.3 Weather Derivatives Pricing Approaches . . . . . . . . . . . . . . . . 14

2.3.1 Historical Burn Analysis . . . . . . . . . . . . . . . . . . . . . 14

2.3 .2 Index Modelling . . . . . . . . . . . . . . . . . . . . 15

2.3.3 Daily Average Temperature Modelling . . . . . . . . . . . . . . . . . . . 15

2.4 Monte Carlo Simulation . . . . . . . . . . . . . . . . . . . . 16

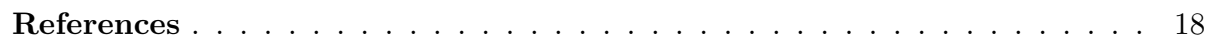

\section{INCLUDED PAPERS}

I. Regime Switching Models on Temperature Dynamics 



\section{Introduction}

\subsection{General Introduction}

Weather derivatives emerged as an interesting and attractive new class of financial instruments since its inception in 1990s when Aquila Energy company structured the first contract of its kind for commodity hedge with the Consolidated Edson (ConEd) company with a weather clause embedded in the contract $[40,4]$. The deregulation of the energy sector in the developed countries aiming at providing reliable services at reasonable prices led to the competition among the producers, which in turn gave customers a choice of energy suppliers. In order for these companies to remain competitive in the business and increase their profits, they were forced to gain new knowledge and skills on how to trade in financial instruments, which requires continuous reassessment of risk exposure for their businesses. An important aspect of business risk exposure, which is usually overlooked by energy producers in their consideration, is how weather variations affect energy demand (volumetric risk) which in turn affects company's profit. The ability to reduce weather risk is an important instrument for hedging purposes in order to stabilize the company's cash flow.

Apart from energy sector, weather fluctuations have many impacts to other business sectors like supermarket, leisure industry, tourism industry as well as agricultural industry [23]. The types of impacts of weather on business range from small reductions in revenues, such as when a shop attracts fewer customers on a rainy day to a total disaster such as when a tornado destroy a factory. According to a report given by US Department of Commerce, $70 \%$ of American companies and $22 \%$ of the American GDP are influenced by weather [27]. For instance, in the northern part of USA, there was warm weather during the winter 2006 that prompted a drastic decline in the demand for winter clothes such as sweaters and coats [12]. From these few examples of adverse weather effects, it shows that weather continuously poses significant financial risk to almost all kinds of businesses.

For individuals and business organizations or companies to hedge such weather related financial risks, a financial instrument called weather derivative was introduced in the financial 
market in the form of Swaps, Options and Futures whose payouts are dependent on the weather. A weather derivative is an agreement between two parties that specifies the flow of payments between the two parties depending on the occurrence of the particular weather variable during the contract period [41]. The underlying weather variables in these financial contracts can be temperature, precipitation or snowfall, wind and humidity. The most commonly used variables in weather derivatives are temperature and precipitation. The major participants in the weather derivatives market include energy companies, insurance and reinsurance companies, market markers, brokers and other retail participants like agriculture, transport, entertainment and tourism firms [23]. Currently, weather derivatives contracts are listed in major derivatives exchanges like Chicago Mercantile Exchange (CME) for various cities in America, Europe and Asia [25].

Most of the studies conducted in weather modelling and weather derivatives pricing are based on the single regime stochastic processes, but a single regime stochastic process may not always describe properly the dynamics of weather (particularly temperature in this case) due to the existence of switching behavior from one stochastic state to another. The switching behavior of temperature dynamics is induced by variety of factors like urbanization, deforestation and changes of weather measurement station. Therefore, this study introduces a regime switching model with heteroskedastic mean-reverting process to capture the switching behaviour in temperature dynamics contributed by the factors mentioned above. The model is then used to price various weather derivative contracts written on temperature indices like heating degree days (HDDs), cooling degree days (CDDs) and cumulative average temperature (CAT).

\subsection{Statement of the Problem}

Weather derivatives are important financial instruments in hedging weather-related risks, since many businesses are largely exposed to weather variations. For weather derivatives to be effective in risk aversion, appropriate models that lead to appropriate pricing methods are important. So it is necessary that, formulated mathematical models include most of the necessary features of the underlying weather variable, like seasonality, trends, switching effects caused by natural effects and various human activities. In that regard, the regimeswitching models presented in this thesis can capture most of the necessary features of the temperature dynamics. 


\subsection{Thesis Structure}

The remaining part of this thesis is mainly structured into two parts; The first part gives a theoretical background to the problem. We give the preliminary mathematical concepts on weather derivatives and weather indices, the stochastic processes, approaches in pricing of weather derivatives and Monte Carlo simulation. The second part consists of the two research papers as shown in summary of papers.

\subsubsection{Summary of Papers}

\section{Paper I: Regime-Switching models on Temperature dynamics}

Emanuel Evarest, Fredrik Berntsson, Martin Singull and Wilson M. Charles. Regime Switching Models for Temperature Dynamics. International Journal of Applied Mathematics and Statistics: 56(2): 19-36, 2017.

This paper gives another way of modelling the dynamics of temperature process for the purpose of weather derivatives pricing. The model is built on the model proposed by Elias et al. [16], where our model introduces heteroskedasticity in the mean-reverting process in the base regime. We show that our new model is relatively better in capturing the temperature dynamics by comparing the corresponding heating degree days (HDDs), cooling degree days (CDDs) and cumulative average temperature (CAT) of the two models with the HDDs, CDDs and CAT from the real data.

\section{Paper II: Pricing of Weather derivatives by Using Regime Switching Model}

Emanuel Evarest, Fredrik Berntsson, Martin Singull and Xiangfeng Yang. Weather Derivatives Pricing using Regime Switching Model. Submitted to International Journal of Computer Mathematics, 2017.

In this paper, we adopt the model from Paper I to price the weather derivative contracts written on temperature indices. We formulate the dynamics of temperature process under the equivalent probability measure by introducing the market price of risk, through the Girsanov's theorem. The mathematical equations for pricing the futures and options for CAT, CDDs and HDDs indices are developed. The Monte Carlo simulation method is employed to get the explicit expected payoff for options written on HDDs, CDDs and CAT indices for the specified contracts. 



\section{Theoretical Background}

\subsection{Weather Derivatives and Weather Indices}

Weather derivatives are financial contracts whose payoff depend on the underlying weather variable(s). The underlying weather variables can be temperature, precipitation, snowfall, humidity or wind. These instruments differ from other derivatives because the underlying asset has no value and it can not be stored. Thus, these weather variables are indexed in order to make them tradable like other index products such as stock indexes. For example, in case of temperature, quantification is in terms of how much the temperature deviates from daily, monthly or seasonal average temperature in a particular city or region. The variations are then adjusted to indexes with a currency (dollar, euro etc) amount attached to each index point [40].

The effects of weather to different entities are not the same. So, in order to hedge these different kinds of risk associated with weather, it is important to know the underlying weather variable(s) defining weather derivatives. The most commonly used weather variable is temperature due to its strong influence on financial performance. Temperature values can be expressed in form of hourly values, daily minimum and maximum as well as daily averages. The most commonly used temperature indices for weather derivative contracts are degree days, average temperature, cumulative average temperature and event indices.

Definition 2.1.1. A Degree day is the difference between a reference temperature and the average temperature on a given day.

The daily average temperature $T_{d}(t)$ on day $t$ is defined as

$$
T_{d}(t)=\frac{T_{\max }(t)+T_{\min }(t)}{2},
$$

where $T_{\max }(t)$ and $T_{\min }(t)$ are the maximum and minimum temperatures on day $t$ respectively [1]. Most literature in weather derivatives defines the reference temperature as the 
temperature level at which heating or cooling systems are switched on or off. We denote this reference temperature by $T_{r e f}$. The standard value of this reference temperature is taken as $18^{\circ} \mathrm{C}$ (or $65^{\circ} \mathrm{F}$ ) [23]. This is because weather conditions may rise above $T_{r e f}$ during the summer and fall below $T_{\text {ref }}$ during the winter. The temperature movements are not symmetrical about the reference $T_{\text {ref }}$. It is possible though not very often that the temperature will fall below $T_{r e f}$ during the summer and it may also rise above or not at all during the winter.

Degree day temperature indices come in two types; namely heating degree days (HDDs) and cooling degree days (CDDs).

Definition 2.1.2. Heating degree day indices are measures of how cold the day was. It gives information on the amount of degrees of temperature on which the daily average temperature $T_{d}(t)$ was lower than the reference temperature $T_{\text {ref }}$. It is given by

$$
H D D(t)=\max \left\{0, T_{\text {ref }}-T_{d}(t)\right\}
$$

Then, HDDs index $z$ over $N$ days is the sum of HDDs over all days during the contract period. It is given by

$$
z=\sum_{t=1}^{N} H D D(t) .
$$

Definition 2.1.3. Cooling degree day indices measures how hot the day was. It tells us how many degrees of temperature the daily average temperature $T_{d}(t)$ was above the reference temperature $T_{\text {ref }}$. It is given by

$$
C D D(t)=\max \left\{0, T_{d}(t)-T_{r e f}\right\}
$$

Then, $C D D$ s index $z$ over $N$ days period is the sum of CDDs over all days during the contract period. i.e.,

$$
z=\sum_{t=1}^{N} C D D(t) .
$$

CDDs are of most relevant to participants in the gas market because more electricity now days is generated from natural gas.

The popularity of degree day indices in the weather market is due to the fact that they measure the amount of energy used by customers in their heating systems or air conditioners. For instance, in US there is high correlation between HDDs and power and gas use [23]. Also the consumption of gas is highly correlated with temperature variations (i.e., $R^{2}=0.9516$ ) $[10]$. 
Definition 2.1.4. Average of temperature indices is the average of daily average temperature $T_{d}(t)$ values over the contract period. For a contract period of $N$ days we have

$$
\bar{T}=\frac{1}{N} \sum_{n=1}^{N} T_{d}(t) .
$$

Average of average temperature indices are mainly used in Japan and seldomly in US and Europe. Derivatives contracts whose underlying is average of average temperature indices are regarded as Asian averaging or Pacific Rim [23, 5].

Definition 2.1.5. Cumulative average temperature (CAT) indices are the sum of the daily average average temperature $T_{d}(t)$ values over the contract period. For the contract period of $N$ days, we have

$$
z=\sum_{t=1}^{N} T_{d}(t) .
$$

CAT are mainly used in Europe during the summer because Northern European summer temperatures does not often exceed the typical used reference temperature [23].

Definition 2.1.6. Event indices are number of days over the contract period that some particular meteorological event occurs, e.g., temperature exceeding some threshold. These events are also known as critical day indices.

Because of the specific nature of these indices, they are often designed in the primary market (i.e., between the hedgers and speculators). A particular example of transactions in these indices could be to provide insurance for construction workers in the event that frost could occur. The weather contract is dependent on the number of frost days from November to March. The event will materialize/occur if on working day (excluding weekends and public holidays) the temperature at 7 a.m. was below $-3.5^{\circ} \mathrm{C}$ or at 10 a.m. was below $-1.5^{\circ} \mathrm{C}$ or the temperatures at 7 a.m. and 10 a.m. were both below $-0.5^{\circ} \mathrm{C}$.

\subsubsection{Weather Derivatives Contracts}

Weather derivatives are mainly structured as swaps, futures and call/put options based on different underlying weather indices. A standard weather derivative contract can be formulated by specifying the following parameters [41];

(i) Contract period (e.g., from 1 July to 30 September 2015),

(ii) Contract type (swap, call or put), 
(iii) An official weather station from which weather measurements are taken,

(iv) A weather variable $(z)$ measured at weather station over the contract period,

(v) Strike,

(vi) Tick,

(vii) Premium (depending on type of contract).

Swaps are contracts in which two parties agree to exchange cash flows in future according to predetermined formula [22]. The exchanges of cash occur at predefined dates or intervals over the contract period. Exchange traded weather swaps contracts involve daily settlement as the index fluctuates, while the OTC traded swaps are only settled at maturity stage. The swaps contract with only one period of settlement can therefore be thought of as forward contracts, while the exchange traded weather swaps are known as futures contracts.

For instance, for a long swap contract, the payoff function is given by

$$
p(z)=\left\{\begin{array}{l}
-C \text { if } z<C_{1}, \\
D(z-K) \text { if } C_{1} \leq z \leq C_{2}, \\
C \text { if } z>C_{2}
\end{array}\right.
$$

where $C$ is the limit expressed in currency terms, $C_{1}$ and $C_{2}$ are lower and upper limits expressed in units of index, while $D$ is the tick and $K$ is the strike. For more details on payoff functions for different weather derivatives contracts see [23].

Example 2.1.1. The London-based chain of wine bars Corney $\&$ Barrow during the summer in the year 2000, bought coverage to protect itself against bad weather, which would reduce its sales. Under the terms of the deal, if the temperature fall below $24^{\circ} \mathrm{C}$ on Thursdays or Fridays between June and September, the company received a payment. The payments were fixed at $£ 15000$ per day, up to a maximum limit of $£ 100000$ in total for the whole period.

\subsection{Stochastic Calculus}

A stochastic process is a collection of random variables $\left\{X_{k} ; k \in K\right\}$ defined on the same probability space $(\Omega, \mathcal{F}, \mathbb{P})$, where $\Omega$ is a sample space, $\mathcal{F}$ is a $\sigma$-algebra of measurable subsets of $\Omega$ whose elements are events and $\mathbb{P}$ is the probability measure such that $\mathbb{P}: \mathcal{F} \rightarrow[0,1]$. If the index set $K$ is discrete, then the process $\left\{X_{k} ; k \in K\right\}$ is called discrete stochastic process and for a continuous index set $K$, the process $\left\{X_{k} ; k \in K\right\}$ is called continuous stochastic 
process. Furthermore, the values taken by the random variable $X_{k}$ can either be discrete or continuous, and thus, the corresponding stochastic process is called discrete-valued or continuous-valued, respectively. For instance, the stock price between 10:00 and 11:00 is continuous time-discrete variable process. If $X_{k}$ represents the temperature at the end of the $k^{t h}$ hour of the day, then $\left\{X_{k} ; 1 \leq k \leq 24\right\}$ is a discrete time-continuous variable process.

Definition 2.2.1. A stochastic process $\left\{X_{k}\right\}$ is called a discrete time-discrete variable Markov chain, if for each $k$ and every $i_{0}, \ldots, i_{k}$,

$$
P\left\{X_{k+1}=j \mid X_{0}=i_{0}, X_{1}=i_{1}, \ldots, X_{k}=i_{k}\right\}=P\left\{X_{k+1}=j \mid X_{k}=i_{k}\right\} .
$$

That is, the future values of the variable depend only on the present value of the variable regardless on how the variable reached its present value.

In the Definition 2.2.1 above, $P\{Y=y \mid X=x\}$ denotes the conditional probability defined by

$$
P\{Y=y \mid X=x\}=\frac{P\{Y=y, X=x\}}{P\{X=x\}}, \quad P\{X=x\}>0 .
$$

Focusing on the stock market, the Markov property implies that the present stock price is the only relevant information needed to predict the future price, because the current price includes all the informations contained in the past prices of the stock [22]. Similarly, continuous time-continuous variable Markov process can be defined accordingly. A Wiener Process (or standard Brownian motion) is one of the most important type of Markov stochastic process with variety of applications in many fields including mathematical finance.

Definition 2.2.2. A stochastic process $\left\{W_{t}, t \geq 0\right\}$ is called a Wiener process (or Brownian motion) if the following properties are satisfied:

(a) $W_{0}=0$; that means, it starts at zero almost surely.

(b) $W_{t}$ is continuous in $t \geq 0$; that means it has continuous sample paths with no jumps.

(c) It has stationary and independent increments.

(d) $W \sim N(0, t-s)$ for $0 \leq s \leq t$; that means the random variable $W=W_{t}-W_{s}$ has a normal distribution with mean 0 and variance $\sigma_{W}^{2}=t-s$.

Wiener process is an important building block for modelling continuous stochastic processes. It is a Markov process, a Gaussian process, a martingale, a diffusion process and a Levy process. 
From Definition 2.2.2, a generalized Wiener process $\left\{X_{t} ; t \geq 0\right\}$ with any drift rate $\mu$ and any variance expressed in terms of $d W_{t}$ can be retrieved and defined as

$$
d X_{t}=\mu d t+\sigma d W_{t}, \quad t \geq 0
$$

The stochastic process $X_{t}$ has constant drift rate $\mu$ and constant variance $\sigma^{2}$. Further more, equation (2.11) can be used to get another form of stochastic differential equation called Geometric Brownian motion (GBM) whose drift and variance are functions of the process itself. It is defined as

$$
Y_{t}=e^{X_{t}}, \quad t \geq 0 .
$$

The values taken by $Y_{t}$ are nonnegative, and $\ln Y_{t}-\ln Y_{0}$ is normally distributed with mean $\mu t$ and variance $\sigma^{2} t$. Thus, $\frac{Y_{t}}{Y_{0}}$ is $\log$-normally distributed with density function given by

$$
f_{Y}(y, t)=\frac{1}{y \sqrt{2 \pi \sigma^{2} t}} \exp \left(-\frac{(\ln y-\mu t)^{2}}{2 \sigma^{2} t}\right), \quad y \geq 0 .
$$

GBM is the most widely used model for stock price changes [40], and it is a generalized Wiener process with drift and variance being functions of variable process and time.

Definition 2.2.3. Given a probability space $(\Omega, \mathcal{F}, \mathbb{P})$ with a sequence $\left\{\mathcal{F}_{t} ; t \geq 0\right\}$ of increasing sub-sigma algebras of $\mathcal{F}$, then $X_{t}$ is said to be $\mathcal{F}_{t}$-adapted if $X_{t}$ is $\mathcal{F}_{t}$-measurable for all $t \geq 0$. If $\mathcal{F}_{t}=\sigma\left(X_{0}, X_{1}, \cdots, X_{t}\right)$, then $\left\{\mathcal{F}_{t} ; t \geq 0\right\}$ is called a sequence of natural filtration.

Another important type of stochastic processes is martingales defined below.

Definition 2.2.4. A stochastic process $X_{t}$ is called a martingale with respect to the filtration $\left\{\mathcal{F}_{t} ; t \geq 0\right\}$ on some probability space $(\Omega, \mathcal{F}, \mathbb{P})$ if the following properties are satisfied

(a) $X_{t}$ is $\mathcal{F}_{t}$-adapted,

(b) $E\left[\left|X_{t}\right|\right]<\infty$,

(c) $E\left[X_{t} \mid \mathcal{F}_{s}\right]=X_{s}$ for $0 \leq s \leq t$.

If the equality sign in (c) of Definition 2.2.4 is replaced by $\leq$ or $\geq$, then $X_{t}$ is said to be a supermartingale or submartingale, respectively. For more details about martingales, see $[15,19,33,29]$. 


\subsubsection{Itô Processes and its Applications}

Construction of pricing models for derivatives requires calculus tools (like Itô integrals and differentials together with Itô formula) that allow us to perform mathematical operations on functions of stochastic random variables. This is due to the fact that the price of a derivative is a function of the underlying asset price which is modelled by a stochastic process [28].

Definition 2.2.5. A stochastic process $X_{t}$ is said to be Itô integrable on the interval $[0, t]$ if $X_{t}$ is predictable and $\mathbb{E}\left(\int_{0}^{t} X_{s}^{2} d s\right)<\infty$.

Itô integral can be defined as the limit in probability as

$$
I_{t}(X)=\int_{0}^{t} X_{s} d W_{s}=\lim _{n \rightarrow \infty} \sum_{k=1}^{n-1} X_{s_{k}}\left(W_{s_{k+1}}-W_{s_{k}}\right) .
$$

Itô integral $I_{t}(X)$, is $\mathcal{F}_{t}$-adapted and its expectation is zero. Other properties of $I_{t}(X)$ includes linearity and martingale. We state the following proposition (see [3, 30, 28, 26] for the proofs).

Proposition 2.2.1. The following properties are true for $I_{t}(X)$

(a) $I_{t}(a X+b Y)=a I_{t}(X)+b I_{t}(Y), \quad \forall a, b \in \mathbb{R}$,

(b) The quadratic variation of $I_{t}(X)$ on $[0, t]$ is $\int_{0}^{t} X_{s}^{2} d s$,

(c) $\mathbb{E}\left[\int_{0}^{t} X_{s} d W_{s}\right]^{2}=\int_{0}^{t} \mathbb{E}\left[X_{s}^{2}\right] d s$ (Itô isometry property).

The above properties are important in solving the stochastic differential equations describing the dynamics of weather variables. Thus, they play a major role in deriving the price process of the weather derivatives on different indices.

Theorem 2.2.1 (Itô formula). Suppose that a stochastic process $X_{t}$ defined by

$$
X_{t}=X_{0}+\int_{0}^{t} \mu_{s} d s+\int_{0}^{t} \sigma_{s} d W_{s}
$$

with stochastic differential

$$
d X_{t}=\mu_{t} d t+\sigma_{t} d W_{t}, \quad \text { for } \quad 0 \leq t \leq T .
$$

Let $f(x, t)$ be twice continuously differentiable function and let $Y=f\left(X_{t}, t\right)$ be an Itô process. Then the Ito formula for computing the stochastic differential of the stochastic function $Y$ is given by

$$
d Y=\left[\frac{\partial f}{\partial t}\left(X_{t}, t\right)+\mu_{t} \frac{\partial f}{\partial x}\left(X_{t}, t\right)+\frac{1}{2} \sigma_{t}^{2} \frac{\partial^{2} f}{\partial x^{2}}\left(X_{t}, t\right)\right] d t+\sigma_{t} \frac{\partial f}{\partial x}\left(X_{t}, t\right) d W_{t} .
$$


Proof. Expanding $\Delta Y$ using Taylor series expansion up to the second order term we have,

$$
\Delta Y=\frac{\partial f}{\partial t} \Delta t+\frac{\partial f}{\partial x} \Delta X+\frac{1}{2}\left(\frac{\partial^{2} f}{\partial t^{2}} \Delta t^{2}+2 \frac{\partial^{2} f}{\partial x \partial t} \Delta X \Delta t+\frac{\partial^{2} f}{\partial x^{2}} \Delta X^{2}\right)+\mathcal{O}\left(\Delta X^{3}, \Delta t^{3}\right)
$$

Since the limits $\Delta X \rightarrow 0$ and $\Delta t \rightarrow 0$, using multiplication rules, $d X^{2}=\sigma_{t}^{2} d t, d X d t=0$ and $d t^{2}=0$, then

$$
\begin{aligned}
d Y & =\frac{\partial f}{\partial t} d t+\frac{1}{2} \sigma_{t}^{2} \frac{\partial^{2} f}{\partial x^{2}} d t+\frac{\partial f}{\partial x} d X \\
& =\frac{\partial f}{\partial t} d t+\frac{1}{2} \sigma_{t}^{2} \frac{\partial^{2} f}{\partial x^{2}} d t+\frac{\partial f}{\partial x}\left(\mu_{t} d t+\sigma_{t} d W_{t}\right) \\
& =\left[\frac{\partial f}{\partial t}+\mu_{t} \frac{\partial f}{\partial x}+\frac{1}{2} \sigma_{t}^{2} \frac{\partial^{2} f}{\partial x^{2}}\right] d t+\sigma_{t} \frac{\partial f}{\partial x} d W_{t} .
\end{aligned}
$$

Example 2.2.1. Let $f=W_{t}^{2}$, where $W_{t}$ is a Wiener process. Applying the Ito formula in the interval $[0, t]$, we get

It follows that

$$
\frac{\partial f}{\partial t}=0, \quad \frac{\partial f}{\partial x}=2 W_{t}, \quad \frac{\partial^{2} f}{\partial x^{2}}=2
$$

$$
W_{t}^{2}=t+2 \int_{0}^{t} W_{s} d W_{s}
$$

which implies that

$$
\int_{0}^{t} W_{s} d W_{s}=\frac{1}{2} W_{t}^{2}-\frac{1}{2} t
$$

Example 2.2.2. Consider a stock price process $S_{t}$ given by an exponential Wiener function

$$
S_{t}=S_{0} e^{\left(\mu-\frac{\sigma^{2}}{2}\right) t+\sigma W_{t}}, \quad S_{0}>0
$$

and let $X_{t}=\left(\mu-\frac{\sigma 2}{2}\right) t+\sigma W_{t}$. Then, $X_{t}=\ln \frac{S_{t}}{S_{0}}$.

The partial derivatives of $S$ are given by

$$
\frac{\partial S}{\partial t}=0, \quad \frac{\partial S}{\partial x}=S \quad \text { and } \quad \frac{\partial^{2} S}{\partial x^{2}}=S .
$$

Using Itô formula, we have

$$
d S_{t}=\mu S_{t} d t+\sigma S_{t} d W_{t} .
$$




\subsubsection{Change of Measure and Girsanov's Theorem}

Given a probability space $(\Omega, \mathcal{F}, \mathbb{P})$, let $Z \geq 0$ be a random variable such that $\mathbb{E}(Z)=1$. Then, we can define another measure $\mathbb{Q}$ on $(\Omega, \mathcal{F})$ by

$$
\mathbb{Q} A=\int_{A} Z d \mathbb{P}, \quad A \in \mathcal{F} .
$$

The variable $Z$ is often written as $\frac{d \mathbb{Q}}{d \mathbb{P}}$ and is called Radon-Nikodym derivative of $\mathbb{Q}$ with respect to $\mathbb{P}[26]$. If $Z>0$ almost surely, then $\mathbb{P}$ is absolutely continuous with respect to $\mathbb{Q}$, with $\frac{d \mathbb{P}}{d \mathbb{Q}}=\frac{1}{Z}$. In this case the measures $\mathbb{P}$ and $\mathbb{Q}$ are said to be equivalent (i.e., $\mathbb{P} \sim \mathbb{Q}$ ) if and only if they have the same null sets i.e., $\mathbb{P} A=0 \Longleftrightarrow \mathbb{Q} A=0$.

Now, we state a useful theorem in the theory of derivatives pricing called Girsanov's theorem. It describes how an underlying asset or instrument from physical measure will take value(s) in the risk-neutral measure. The proof of the Theorem 2.2.2 can be found in [26].

Theorem 2.2.2 (Girsanov's Theorem). Let $\left(\Omega, \mathcal{F},\left\{\mathcal{F}_{t}\right\}_{t \in[0, T]}, \mathbb{P}\right)$ be a filtered probability space, $\left(W_{t}\right)_{0 \leq t \leq T}$ is a Brownian motion on this space and $\gamma$ is a constant. Define

$$
Z_{t}=\exp \left(-\gamma W_{t}-\frac{1}{2} \gamma^{2} t\right), \quad 0 \leq t \leq T .
$$

Then the process $W_{t}^{*}$ defined by

$$
W_{t}^{*}=W_{t}+\gamma t, \quad 0 \leq t \leq T
$$

is a Brownian motion on the probability space $(\Omega, \mathcal{F}, \mathbb{Q})$, where $Z_{T}=\frac{d \mathbb{Q}}{d \mathbb{P}}$ and $\mathbb{P} \sim \mathbb{Q}$.

Example 2.2.3. Consider the stochastic differential equation (Geometric Brownian motion) given by

$$
d X_{t}=\mu X_{t} d t+\sigma X_{t} d W_{t}
$$

Let's define

$$
W_{t}^{*}=W_{t}+\frac{\mu}{\sigma} t
$$

Then

$$
d W_{t}^{*}=d W_{t}+\frac{\mu}{\sigma} d t
$$

Putting (2.29) into (2.28) we get

$$
d X_{t}=\mu X_{t} d t+\sigma X_{t}\left(d W_{t}^{*}-\frac{\mu}{\sigma} d t\right)=\sigma X_{t} d W_{t}^{*} .
$$

By Girsanov's Theorem, $W_{t}^{*}$ is a Brownian motion on the probability space $(\Omega, \mathcal{F}, \mathbb{Q})$, where $\mathbb{Q} A=\int_{A} \exp \left(-\frac{\mu}{\sigma} W_{t}-\frac{1}{2} \frac{\mu^{2}}{\sigma^{2}} t\right) d \mathbb{P}, \quad A \in \mathcal{F}$. 


\subsection{Weather Derivatives Pricing Approaches}

Pricing of derivatives involves determination of a fair price of futures or options using one of the several methods and models. For weather derivatives contracts written on temperature indices, methods like historical burn analysis (HBA), index modelling and daily average temperature simulation models are used in pricing weather futures and options contracts [23]. Other approaches for pricing temperature based weather derivatives include indifference method [8]. This method includes price risk, weather/quantity risk and other possible risks in the financial market $[21,11]$. Also, finite difference methods has been used in valuation of weather derivatives in the process of comparing weather derivatives with power derivatives [31].

\subsubsection{Historical Burn Analysis}

HBA is the simplest method for pricing temperature derivatives without modelling the temperature dynamics [23]. The method is based on the idea that how the contract would have performed in the previous years, and the future expected payoff is obtained from the average payoff of the same derivative contract for the past years. For example, for a derivative with contract period $\left[t_{1}, t_{2}\right]$ to be priced for year $k+1$, we need to calculate the fictive indices that the derivatives would have in the previous years $k, k-1, k-2, \ldots$ This gives us a series $X_{1}, X_{2}, \cdots, X_{k}$ of $k$ indices for the past $k$ years, which can be described by the following linear model

$$
X_{j}=a_{0}+a_{1} j+\epsilon, \quad j=1,2, \cdots, k \quad \text { and } \epsilon \sim N\left(0, \sigma^{2}\right),
$$

where the intercept $a_{0}$ and slope the parameter $a_{1}$ are estimated as

$$
a_{1}=\frac{\sum_{j=1}^{k}\left(j-\frac{k}{2}\right)\left(X_{j}-\bar{X}\right)}{\sum_{j=1}^{k}\left(j-\frac{k}{2}\right)} \text { and } a_{0}=\bar{X}-\frac{k}{2} a_{1},
$$

with $\bar{X}=\frac{1}{k} \sum_{j=1}^{k} X_{j}$ being the mean of indices for the past $k$ years.

HBA basically relies on the following two main assumptions; first, the historical temperature time series is stationary and statistically consistent with the weather that will happen during the contract period. Second, the data values for different years are independent and identically distributed $[32,36]$. The presence of seasonality, jumps and trends in temperature time series shows that none of the HBA assumptions are correct [38]. Another observation 
revealed that, these assumptions can be correct if the temperature data sets are detrended and cleaned, but still their results of the pricing remain inaccurate and subject to large pricing errors $[24,23,7]$. Also, in HBA framework the market price of risk for temperature derivatives can not be estimated $[10,20]$.

\subsubsection{Index Modelling}

Index modelling is another approach for pricing temperature derivatives, where one can model temperature indices directly. In this approach each of the temperature indices HDDs, CDDs, CAT and Pacific Rim must be modelled separately. Consider the case of modelling the accumulated HDDs index given by [14], where the accumulated HDDs $Z$ is modelled by lognormal process given by

$$
d Z_{t}=v Z_{t} d t+\sigma Z_{t} d W_{t}
$$

where $v$ is the drift parameter, $\sigma$ is the volatility parameter and $W_{t}$ is a Wiener process. Then at the exercise time $T$,

$$
Z_{T}=\exp \left(m(T)+\sigma W_{T}\right), \quad \text { where } \quad m(T)=\log Z_{0}+\left(v-\frac{1}{2} \sigma^{2}\right) T .
$$

The results in [14] of the model after testing with real data from Birmingham England, show that, the model is convenient but still affects the pricing, and the choice of initial value $Z_{0}$ has significant effect on the option prices by $\pm 10 \%$. Although this approach is simple, effective and can produce superior results compared to HBA, building a model in this approach requires a rich supply of historical temperature data which is not always possible to achieve $[34,13]$.

\subsubsection{Daily Average Temperature Modelling}

Daily average temperature (DAT) simulation involves using stochastic models to develop the dynamics of temperature on daily basis. This approach for pricing temperature derivatives uses the temperature dynamics models to derive the corresponding indices for pricing various weather derivatives contracts based on temperature. DAT modelling gives more accurate pricing than index and HBA since it includes more complete use of the available historical data, it uses one model for all contracts in a given measurement location, and it becomes easier to incorporate meteorological forecasts into the pricing model $[23,40]$. In this category, various models for temperature dynamics have been presented in pricing weather derivative contracts. This include mean-reverting stochastic models with different modifications of seasonal trends and volatility of the temperature process. For example [1] developed a 
mean-reverting temperature process,

$$
d T_{t}=\left\{\frac{d T_{t}^{m}}{d t}+a\left(T_{t}^{m}-T_{t}\right)\right\} d t+\sigma_{t} d W_{t}
$$

where the volatility $\sigma_{t}$ is a piecewise constant function, with constant value for each month of the year and $T_{t}^{m}$ is the mean temperature at time $t$. Other mean-reverting stochastic processes for temperature dynamics include the mean-reverting with seasonality in the mean level and volatility [5] which can be discretized as AR(1) model. Also mean-reverting process driven by fractional Brownian motion is used for capturing long-dependence in temperature process $[9,2]$. For similar pricing model using single regime mean-reverting processes, see $[6,38,39,35]$. All these approaches use single regime model for temperature dynamics, but a single stochastic process may not describe the dynamics of temperature appropriately because switching behaviour between stochastic processes may exist. As a result [16] presented a regime switching model for temperature dynamics using Canadian data. In the model they assumed that the means and volatilities of the respectively state processes are constants. In our paper [17], we introduce a regime switching model with heteroskedastic mean-reverting process in the base regime, that allows the volatility in base regime to vary with its state temperature and hence general temperature dynamic process to vary accordingly. This gives a wider chance of capturing both the switching behaviour and its volatility for different time points of the temperature dynamics process. Also, in [18], we have used the regime switching model to price various weather derivative contracts written on temperature indices. But the main challenge for most of the DAT models approach in pricing weather derivatives is the complex nature of the dynamics of futures index, which results to the pricing expressions that do not have closed-form solutions. This requires the use of Monte Carlo simulations to achieve the explicit weather derivative contract prices.

\subsection{Monte Carlo Simulation}

Monte Carlo simulation is a technique for estimating integrals and expected values of functions of random variables [37]. Consider a problem of estimating expectation of $f(X)$ for some random variable $X$ given by

$$
\mu=E[f(X)],
$$

where $\mu$ is the unknown fixed number. Different Monte Carlo algorithms for estimating the same expected value can be constructed as follows:

(a) Importance Sampling: Suppose that a random variable $X$ has a density function $g$, we can express

$$
\mu=\int_{\mathbb{R}} f(x) g(x) d x
$$


Then, for an arbitrary density function $h(x) \neq 0$, we have

$$
\mu=\int_{\mathbb{R}} f(x) g(x) d x=\int_{\mathbb{R}} f(x) \frac{g(x)}{h(x)} h(x) d x=E\left[f(x) \frac{g(x)}{h(x)}\right] .
$$

Therefore, the Monte Carlo estimate $\hat{\mu}$ for $\mu$ is given by

$$
\hat{\mu}=\frac{1}{n} \sum_{m=1}^{n}\left[f\left(x_{m}\right) \frac{g\left(x_{m}\right)}{h\left(x_{m}\right)}\right],
$$

where $x_{m} ; m=1,2, \ldots, n$ are independent identically distributed samples of $x$. Note that, $\hat{\mu}$ is a random variable varying depending on the samples.

(b) Control variates: Assume that there is a random variable with $E(Z)=0$. Then we can express

$$
\mu=E[f(X)+Z]
$$

such that, its Monte Carlo estimate $\hat{\mu}$ for $\mu$ is given by

$$
\hat{\mu}=\frac{1}{n} \sum_{m=1}^{n}\left[f\left(X_{m}\right)+Z_{m}\right],
$$

where $\left(X_{m}, Z_{m}\right) ; m=1,2, \ldots, n$ are independent identically distributed samples of $(X, Z)$.

In all these schemes, the Monte Carlo estimate is generally given by

$$
\hat{\mu}=\frac{1}{n} \sum_{m=1}^{n} f\left(X_{m}\right),
$$

where $X_{m} ; m=1,2, \ldots, n$ are independent indentically distributed samples of $X$. Also, Monte Carlo simulation is based on the strong law of large numbers. That is

$$
\hat{\mu}=\frac{1}{n} \sum_{m=1}^{n} f\left(X_{m}\right) \stackrel{\text { a.s. }}{\longrightarrow} \mu \quad \text { as } \quad n \rightarrow \infty .
$$

Generally, the estimate $\hat{\mu}$ is unbiased estimator for $\mu$ i.e.,

$$
E(\hat{\mu})=E\left(\frac{1}{n} \sum_{i=1}^{n} f\left(X_{i}\right)\right)=\frac{1}{n} \sum_{i=1}^{n} E\left(f\left(X_{i}\right)\right)=\mu .
$$

For the case of DAT model used in this thesis, Monte Carlo simulations are used to generate large number of simulated scenarios of temperature time series to determine the possible payoff of the temperature derivative contracts. The fair price of the derivative contract is obtained from the average of all simulated payoffs. 


\section{Future Research}

A possible generalization from this work can be changing the nature of switching from one state to another. That means, instead of $\xi$, one may consider a Markov chain $\left(\xi_{t}\right)_{t \geq 0}$ taking values in $E \subseteq \mathbb{Z}$, with intensity matrix $Q(t)$. The same reasoning used in [18] holds, but the explicit calculations can be difficult to perform.

\section{References}

[1] Peter Alaton, Boualem Djehiche, and David Stillberger. On modelling and pricing weather derivatives. Applied Mathematical Finance, 9(1):1-20, 2002.

[2] Fred Espen Benth. On arbitrage-free pricing of weather derivatives based on fractional brownian motion. Applied Mathematical Finance, 10(4):303-324, 2003.

[3] Fred Espen Benth. Option Theory with Stochastic Analysis: An Introduction to Mathematical Finance. Springer, New York, 2004.

[4] Fred Espen Benth. Modelling Temperature for Pricing Weather Derivatives. Wiley Online Library, 2013.

[5] Fred Espen Benth and Jurate Saltyte Benth. The volatility of temperature and pricing of weather derivatives. Quantitative Finance, 7(5):553-561, 2007.

[6] Fred Espen Benth and Jurate Saltyte-Benth. Stochastic modelling of temperature variations with a view towards weather derivatives. Applied Mathematical Finance, 12(1):53-85, 2005.

[7] Fred Espen Benth and Jurate Saltyte-Benth. Weather derivatives and stochastic modelling of temperature. International Journal of Stochastic Analysis, 2011, 2011.

[8] Patrick L. Brockett, Linda L. Goldens, Min-Ming Wen, and Charles C. Yang. Pricing weather derivatives using the indifference pricing approach. North American Actuarial Journal, 13(3):303-315, 2012.

[9] Dorje C. Brody, Joanna Syroka, and Mihail Zervos. Dynamical pricing of weather derivatives. Quantitative Finance, 2(3):189-198, 2002.

[10] Melanie Cao and Jason Wei. Weather derivatives valuation and market price of weather risk. Journal of Futures Markets, 24(11):1065-1089, 2004. 
[11] René Carmona. Indifference Pricing: Theory and Applications. Princeton University Press, 2009.

[12] Frank Youhua Chen and Candace Arai Yano. Improving supply chain performance and managing risk under weather-related demand uncertainty. Management Science, 56(8):1380-1397, 2010.

[13] Adam Clements, A.S. Hurn, and KA. Lindsay. Estimating the payoffs of temperaturebased weather derivatives. Technical report, National Centre for Econometric Research, 2008 .

[14] Mark Davis. Pricing weather derivatives by marginal value. Quantitative finance, 1:1-4, 2001.

[15] Rick Durett. Probability: Theory and Examples. Cambridge University Press, second edition, 2010.

[16] RS. Elias, MIM. Wahab, and L Fang. A comparison of regime-switching temperature modeling approaches for applications in weather derivatives. European Journal of Operation Research, 232(3), 2014.

[17] Emanuel Evarest, Fredrik Berntsson, Martin Singull, and Wilson M. Charles. Regime switching models for temperature dynamics. International Journal of Applied Mathematics and Statistics, 56(2):19-36, 2017.

[18] Emanuel Evarest, Fredrik Berntsson, Martin Singull, and Xiangfeng Yang. Pricing of weather derivatives using regime switching models. 2017.

[19] Allan Gut. Probability a Graduate Course. Springer, 2005.

[20] Wolfgang Karl Härdle and Brenda López Cabrera. The implied market price of weather risk. Applied Mathematical Finance, 19(1):59-95, 2012.

[21] Vicky Henderson and David Hobson. Utility indifference pricing-an overview. Volume on Indifference Pricing, 2004.

[22] John C. Hull. Options, Futures, and other derivatives. Pearson Education Inc., 9th edition, 2014.

[23] Stephen Jewson and Anders Brix. Weather derivative valuation: the meteorological, statistical, financial and mathematical foundations. Cambridge University Press, 2005.

[24] Stephen Jewson and Rodrigo Caballero. Seasonality in the statistics of surface air temperature and the pricing of weather derivatives. Meteorological Applications, 10(4):367$376,2003$. 
[25] Travis L. Jones. Agricultural applications of weather derivatives. International Business EG Economics Research Journal, 6(6):53-59, 2007.

[26] Hugo D. Junghenn. Option Valuation: A First Course in Financial Mathematics. Taylor \& Francis Group, 2011.

[27] Anne Ku. Betting on Weather, 2001.

[28] Yue-Kuen Kwok. Mathematical Models of Financial Derivatives. Springer, Berlin, second edition, 2008.

[29] Marek Musiela and Marek Rutkoswski. Martingale methods in Financial Modelling. Springer-Verlag Berlin Heidelberg, second edition, 2005.

[30] Benth Oksendal. Stochastic Differential Equations. Springer, New York, second edition, 2003.

[31] Craig Pirrong and Martin Jermakyan. The price of power: The valuation of power and weather derivatives. Journal of Banking 85 Finance, 32(12):2520-2529, 2008.

[32] Frank Schiller, Gerold Seidler, and Maximilian Wimmer. Temperature models for pricing weather derivatives. Quantitative Finance, 12(3):489-500, 2012.

[33] Steven E. Shreve. Stochastic Calculus for finance, Vol I, The binomial asset pricing models. Springer, 2005.

[34] Jiri Svec and Maxwell Stevenson. Modelling and forecasting temperature based weather derivatives. Global Finance Journal, 18(2):185-204, 2007.

[35] Anatoliy Swishchuk and Kaijie Cui. Weather derivatives with applications to canadian data. Journal of Mathematical Finance, 3(1), 2013.

[36] Jon Tindall. Weather derivatives: pricing and risk management applications. Institute of Actuaries of Australia, 2006.

[37] Hui Wang. Monte Carlo Simulations with Applications to Finance. A Chapman \& Hall Book, 2012.

[38] Achilleas Zapranis and Antonis Alexandridis. Modelling the temperature timedependent speed of mean reversion in the context of weather derivatives pricing. Applied Mathematical Finance, 15(4):355-386, 2008.

[39] Achilleas Zapranis and Antonis Alexandridis. Weather derivatives pricing: Modeling the seasonal residual variance of an ornstein-uhlenbeck temperature process with neural networks. Neurocomputing, 73(1):37-48, 2009. 
[40] Achilleas Zapranis and Antonis K. Alexandridis. Weather derivatives Modeling and Pricing weather related risk. Springer New York, 2013.

[41] Lixin Zeng. Weather derivatives and weather insurance: concept, application, and analysis. American Meteorological Society, (81):2075-2082, 2000. 



\section{Papers}

The articles associated with this thesis have been removed for copyright reasons. For more details about these see:

http://urn.kb.se/resolve?urn=urn:nbn:se:liu:diva-139253 